\title{
Digital Payments Adoption Research: A Meta-analysis for Generalising the Effects of Attitude, Cost, Innovativeness, Mobility and Price Value on Behavioural Intention
}

\author{
Pushpa Patil $^{1}$, Nripendra P. Rana ${ }^{2}$, Yogesh K. Dwivedi ${ }^{3}$ \\ ${ }^{1}$ Emerging Markets Research Centre (EMaRC), School of Management, Swansea University \\ Bay Campus, Swansea, SA1 8EN, UK \\ \{919286@swansea.ac.uk; papushp@gmail.com\} \\ ${ }^{2}$ Emerging Markets Research Centre (EMaRC), School of Management, Swansea University \\ Bay Campus, Swansea, SA1 8EN, UK \\ \{n.p.rana@swansea.ac.uk\} \\ ${ }^{3}$ Emerging Markets Research Centre (EMaRC), School of Management, Swansea University \\ Bay Campus, Swansea, SA1 8EN, UK \\ \{y.k.dwivedi@Swansea.ac.uk\}
}

\begin{abstract}
The rapid evolution of mobile based technologies and applications has led to development of several different forms of digital payment methods (DPMs) but with limited enthusiasm in consumers for adopting them. Hence, several academic studies have already been conducted to examine role of various antecedents that determines consumers' intention to adopt DPMs. The degree of effect and significance of several antecedents found to be inconsistent across different studies. This provided us a basis for undertaking a meta-analysis of existing research for estimating the cumulative effect of such antecedents. Therefore, this study aimed to perform a meta-analysis of five antecedents (namely, attitude, cost, mobility and price value) for confirming their overall influence on intentions to adopt DPMs. The results of this study suggest that the cumulative effect of four (of five antecedents) found to be significant, while influence of price value was insignificant. The recommendations drawn from this research would help to decide if and when to use such antecedents for predicting consumer intention to adopt DPMs.
\end{abstract}

Keywords: Adoption, Cashless Payments, Digital Payments, Meta-analysis, Mobile Payments

\section{Introduction}

There have been rapid advances in evolution of information and communication technologies (ICT) including wireless handheld devices such as smartphones both in terms of their technological capability and fast reduction in their purchase cost for consumers. Widespread availability of smartphones and other handheld devices with internet connectivity is providing conducive environment for innovation development and commercialisation in various areas including digital payment methods (DPMs). In the past two decades a wide range of new functionalities has been developed and 
added to mobile and portable devices supporting different forms of financial services for example, bill payments, account transfers, person-to-person transfers, electronic point of sales payment, remote payments for purchasing goods and services as well as other types of services such as mobile marketing, ticketing, discounts or coupon (Oliveira et al., 2016). Majority of consumer oriented DPMs are mobile payment (mpayment) systems, which refers to making payments for goods and services using mobile devices including wireless handsets, personal digital assistants, radio frequency devices and near field communication-based devices (Chen and Nath, 2008; Slade et al. 2013; 2014).

Despite the availability of various forms of mobile based DPMs and the encouraging possibility provided by the m-payment systems, their penetration and adoption are relatively low in comparison to the other recent forms of cashless payments mode (or DPMs) including credit card and online payments. For example, only $17.1 \%$ of mobile Internet users have ever used m-payments in China whereas in the US, this figure is 12\% (Garrett et al., 2014; Smith et al., 2012; Zhou, 2014). A similar trend of low adoption rates for the m-payment systems have been witnessed in several European countries such as the UK and France (Kapoor et al., 2014; Slade et al. 2013; 2014). Although m-payment offers a number of benefits including ubiquity, convenience and value to users, it also involves great deal of uncertainty and risk due to virtuality and lack of control (Lin et al., 2014; Yan and Yang, 2014), which might have impact on consumer attitude towards emerging DPMs (Hossain \& Mahmud, 2016; Liebana-cabanillas, 2015ab; Schierz et al., 2010; Tian and Dong, 2013). There is a cost for owning appropriate devices, having internet connectivity and sometime there is a fee for making mobile based transactions, which may or may not be influencing consumers' intention towards mobile based DPMs (Lu et al. 2011; Phonthanukitithaworn et al., 2015; Zhou 2011). Relating to cost and fee, existing research has also examined the role of price value (Oliveira et al. 2016; Slade et al. 2015a). One of major advantages of mobile based DPMs over other types of DPMs (such as e-banking) is its portability/mobility from one place to other place, which makes anytime anywhere payment feasible. Considering that some studies (such as Liu 2012; Schierz et al. 2010) have already examined the role of mobility for explaining consumer intention to adopt. Similarly, many studies (namely, Liebanacabanillas 2015; Makki et al. 2016; Oliveira et al. 2016; Sam et al. 2014; Slade et al. 2015b; Thakur \& Srivastava 2014; Yang et al. 2012) have argued that consumers' innovativeness may have significant influence on forming consumer intention towards DPMs. Considering the importance of such constructs, various existing adoption studies have integrated them with dominant technology adoption models (such as IDT, TAM, UTAUT and UTAUT2) for explaining consumer intention to adopt DPMs. Effect of some of these constructs have been consistent (across different studies) in terms significance but their extent of influence vary study to study. But for some constructs both significance level and degree of influence varies across different studies.

Integration and synthesis of existing results about these constructs is essential for better understanding of the overall influence of such constructs on intention to adopt DPMs. An initial literature review suggested that there is no existing work yet that have either done systematic literature review or meta-analysis around these constructs 
in relation to DPMs. Therefore, in order to understand the overall influence (by estimating cumulative effect size) of theoretical constructs (namely, attitude, cost, mobility, price value and innovativeness) on intention to adopt DPMs, the aim of this study is to undertake the meta-analysis of findings reported in the existing research. This is to be noted that although there are many other external constructs that are important for explaining intention to and usage of DPMs, focus of this submission is to review and integrate results of aforementioned five constructs only due to space limitations. This study is part of a larger project so subsequent outputs would cover other important constructs.

The remaining part of this submission is structured as follows: Section 2 describes research and analysis method, which is followed by a descriptive review around constructs of interest in Section 3. The meta-analysis results are then presented in Section 4. Finally, conclusions, limitations and future research directions are presented in Section 5.

\section{Research Method}

The purpose of this study is to analyse and integrate results from existing studies. Hence, the first step was to identify relevant empirical research work on digital payment methods/systems adoption, which was undertaken by employing a keywordbased search. The following keywords were searched in the Scopus database: "Digital Payment" OR "Cashless Payment" OR "Mobile Payment" AND "Adoption” OR "Acceptance” OR "Diffusion” OR "Usage” OR “Intention” OR "Success” OR "Satisfaction". Although, a total of 109 studies were appeared in initial search results, but after a screening it was found that only 80 studies were directly appropriate for inclusion in the literature analyses focussed on consumer adoption and use of digital payment methods. It is important to note that some conference papers were not accessible through researcher's library, hence total number further reduced to 75 studies. A further detailed screening and analysis was conducted to identify various independent variables (IVs) employed to determine influence of different dependent variables (DVs) such as behavioural intention (BI), usage (U), satisfaction and continuance intention. This was achieved by collecting the information regarding name of IVs and DV along with types of relationships (significant, insignificant or conceptual) reported between them (See Tables 1-2). Although, several different relationships were identified through literature analysis, we decided to focus on 23 existing studies that had examined effects of attitude, cost, mobility, price value and innovativeness on determining intention to adopt digital payment systems. This is simply due to page limits and other reasons as discussed in the previous sections. Further details about these 23 studies have been provided in both Tables 1 and 2 .

The second step of this study was to undertake a narrative review for descriptively analysing 23 studies focussing on effect of each independent construct on behavioural intention, which is presented in Section 3. This was then followed by undertaking met-analysis (quantitatively integrating and synthesising results from existing research) for the purpose of generative cumulative effect sizes and significance values (Dwivedi et al. 2017). It is a methodical alternative to a qualitative and descriptive literature analysis and praised by many researchers for being better than a literature 
analysis (Rosenthal, 1991; Rosenthal and DiMatteo, 2001; Wolf, 1986). As illustrated in Table 2, we collected correlation coefficients relating to each relationship along with sample size in order to perform the meta-analysis, which was conducted using comprehensive meta-analysis software tool. Further details about meta-analysis and results obtained from it are described in Section 4.

\section{Descriptive Review}

The literature related to areas of digital payments, mobile payments and mobile banking has already been reviewed by existing studies (See Patil et al. 2017; Slade et al, 2013; 2014). So, it was not considered necessary to conduct a review on digital or mobile payments in general. Rather, focus of review presented in this section given on evaluating and summarising role of constructs (namely, attitude, cost, mobility, price value and innovativeness) examined in this study. As shown in Table 1, a number of existing studies have already empirically examined the role of antecedents such as attitude, cost, mobility, price value and innovativeness. A brief discussion about these studies is provided in remaining part of this section.

Table 1: Existing studies that have utilised Attitude, Cost, Mobility, Price Value and Innovativeness as antecedents of behavioural intention

\begin{tabular}{|c|c|c|c|c|c|c|}
\hline IV & DV & Sig & Non-Sig & App Exa & Context & RespTypes \\
\hline $\mathrm{AT}$ & $\mathrm{BI}$ & $\begin{array}{l}\text { Tian and Dong (2013) } \\
\text { Liebana-cabanillas } \\
(2015) \\
\text { Hossain \& Mahmud } \\
(2016) \\
\text { Schierz et. al (2010) }\end{array}$ & None & $\begin{array}{l}\text { Mobile } \\
\text { Payment } \\
\text { QR Mobile } \\
\text { Payment } \\
\text { System }\end{array}$ & $\begin{array}{l}\text { China } \\
\text { Spain } \\
\text { Bangladesh } \\
\text { Germany }\end{array}$ & $\begin{array}{l}\text { University } \\
\text { Students } \\
\text { Civil Service } \\
\text { College } \\
\text { Students } \\
\text { Consumers }\end{array}$ \\
\hline $\mathrm{CO}$ & BI & $\begin{array}{l}\text { Hongxia et. al (2011) } \\
\text { Lu et al. (2011) } \\
\text { Phonthanukitithaworn } \\
\text { et. al (2015) } \\
\text { Zhou (2011) } \\
\text { Yang et.al (2011) } \\
\text { Yang et al (2012) }\end{array}$ & $\begin{array}{l}\text { Yang et al } \\
\text { (2012) }\end{array}$ & $\begin{array}{l}\text { Mobile } \\
\text { Payment }\end{array}$ & $\begin{array}{l}\text { China } \\
\text { Finland } \\
\text { Thailand }\end{array}$ & $\begin{array}{l}\text { University } \\
\text { Students } \\
\text { Alipay Users } \\
\text { Consumers }\end{array}$ \\
\hline $\mathrm{MO}$ & $\mathrm{BI}$ & $\begin{array}{l}\text { Liu (2012) } \\
\text { Schierz et. al (2010) }\end{array}$ & $\begin{array}{l}\text { Liebana- } \\
\text { cabanillas } \\
(2015) \\
\end{array}$ & $\begin{array}{l}\text { Mobile } \\
\text { Payment } \\
\text { QR Mobile } \\
\text { Payment } \\
\text { System } \\
\end{array}$ & $\begin{array}{l}\text { China } \\
\text { Germany } \\
\text { Spain } \\
\end{array}$ & $\begin{array}{l}\text { University } \\
\text { Students } \\
\text { Consumers } \\
\end{array}$ \\
\hline PV & BI & None & $\begin{array}{l}\text { Oliveira et } \\
\text { al. (2016) } \\
\text { Slade et al. } \\
\text { (2015a) }\end{array}$ & $\begin{array}{l}\text { Mobile } \\
\text { Payment }\end{array}$ & $\begin{array}{l}\text { Portugal } \\
\text { UK }\end{array}$ & $\begin{array}{l}\text { University } \\
\text { Students } \\
\text { Online } \\
\text { Consumers }\end{array}$ \\
\hline IN & BI & $\begin{array}{l}\text { Makki et al (2016) } \\
\text { Slade et al. (2015b) } \\
\text { Oliveira et al. (2016) } \\
\text { Thakur \& Srivastava } \\
\text { (2014) } \\
\text { Liebana-cabanillas } \\
\text { (2015) } \\
\text { Yang et al (2012) }\end{array}$ & None & $\begin{array}{l}\text { NFC Based } \\
\text { MP } \\
\text { Technology } \\
\text { Mobile } \\
\text { Payment } \\
\text { QR Mobile } \\
\text { Payment } \\
\text { System }\end{array}$ & $\begin{array}{l}\text { UK } \\
\text { India } \\
\text { China } \\
\text { Portugal } \\
\text { Spain } \\
\text { USA }\end{array}$ & $\begin{array}{l}\text { Online } \\
\text { Consumers } \\
\text { University } \\
\text { Students } \\
\text { Consumers }\end{array}$ \\
\hline
\end{tabular}

[Legend: ATT: Attitude; COS: Cost; D.V.: Dependant variable; INN: Innovativeness; I.V.: Independent Variable; MOB: Mobility; PV: Price Value] 
As listed in Table 1, four existing studies (Hossain \& Mahmud, 2016; Liebanacabanillas, 2015ab; Schierz et al., 2010; Tian and Dong, 2013) have examined role of attitude for determining consumer intention to adopt digital payment systems in the contexts of both developed (Germany) and developing (Bangladesh, China and Spain) countries. The results suggest that the attitude has significant influence on consumer intention across all four studies. This may provide the case for employing this construct for further examination of emerging digital payment systems adoption across various contexts subject to demonstrating significant cumulative effect size across all existing work. This will be in line with recommendation from a recent meta-analytic study (Dwivedi et al. 2017) that argued for considering role of attitude as a core to a modified UTAUT model.

Five studies (e.g. Lu et al. 2011; Phonthanukitithaworn et al., 2015; Zhou 2011) have examined and reported significant effect of Cost/Perceived Cost/Perceived Fee on BI but only one such study (Yang et al., 2012) has reported non-significant effect of this construct. The effect of cost has been found significant in the context of both developed (Finland) and developing (China and Thailand) countries. Contrastingly, two existing studies (Oliveira et al. 2016; Slade et al. 2015a) reported nonsignificant effect of a similar construct (Price Value from UTAUT2 Theory) for explaining consumer BI. This suggest that a synthesis of existing results using method such as meta-analysis is needed in order to establish whether cost or perceived value is a more relevant construct for examining issues related to digital payment adoption.

The role of 'mobility' as an antecedent of consumer intention to adopt has been examined by three existing studies with two reporting significant (Liu 2012; Schierz et al. 2010) influence in the context of China and Germany and one with nonsignificant effect (Liebana-cabanillas, 2015) in a Spanish context. Given the inconsistency in existing results relating to this construct, it was deemed appropriate to estimate overall effect size and significance of this construct by employing a metaanalytic approach.

Existing literature of innovation adoption (Kapoor et al. 2014ab) has argued and illustrated important role of 'innovativeness' towards influencing intention formation for variety of systems in various contexts. In line with that a total of seven existing studies (Liebana-cabanillas 2015; Makki et al. 2016; Oliveira et al. 2016; Sam et al. 2014; Slade et al. 2015b; Thakur \& Srivastava 2014; Yang et al. 2012) have examined the role of innovativeness for determining intention to adopt digital payment systems in various contexts namely UK, India, China, Portugal, Spain and USA. All these studies have suggested that innovativeness consistently exerts significant influence on BI to adopt digital payment systems in a variety of context. This shows that innovativeness is a relatively robust and important construct, hence should be considered by future adoption studies in this and other similar domains. Therefore, it was considered appropriate to establish its cumulative effect size using meta-analysis approach.

Literature presented in Table 1 also suggest that that existing studies have mainly examined issues related to mobile based payment methods, mobile payment devices such as smartphones, NFC, contactless mobile payments and QR mobile payment 
system. This suggests that other forms of digital payments ${ }^{1}$ yet to be examined. Hence, the term digital payments in this paper is largely represent mobile payments and may have less relevance for any other form of digital payments.

\section{Meta-analysis}

Table 2 presents data (correlation coefficients ( $\beta$ ), significance (p) and sample size) utilised for conducting meta-analysis for relationships between IVs (attitude, cost, price value, mobility and innovativeness) and behavioural intention to adopt digital payment methods that have occurred two or more times across 23 existing studies. Table 2 also presents different theories and models employed by the existing studies that have examined these constructs. Details presented in this table suggest that these constructs were integrated with frequently utilised adoption and diffusion theories and models such as Theory of Reasoned Action (TRA), Technology Acceptance Model (TAM), Theory of Planned Behaviour (TPB), Innovation Diffusion Theory (IDT), UTAUT/UTAUT 2 theories, Trust Transfer Theory as well as self-efficacy and risk constructs. Table 2 also suggest that in a number of studies (\#1, 2, 3, 5, 7, 8, 9, 11, 12, $14,16,18,21,23)$ sample size was below 300 , which is frequently recommended minimum threshold for theory testing particularly for studies that have utilised SEM as a theory testing technique, which may have impact on generalisability and validity of results reported by these studies. This provides added reason and basis for conducting the meta-analysis, which utilise cumulative sample size to overcome such problems. Table 2 also illustrate that some relationships reported significant by some studies but non-significant by some other studies leading to inconsistency and lack of generalisation. In such scenario, meta-analysis helps to determine overall significance of such relationships with inconsistent $p$ values.

Table 2: Details of Existing studies that have utilised Attitude, Cost, Mobility, Price Value and Innovativeness as antecedents

\begin{tabular}{l|l|l|c|c|c|c|c}
\hline$\#$ & \multicolumn{1}{|c|}{ Study } & TU & IV & DV & $\beta$ & $p$ & $\begin{array}{c}\text { Sample } \\
\text { Size }\end{array}$ \\
\hline 1 & Tian and Dong (2013) & $\begin{array}{l}\text { TAM, TPB, } \\
\text { IDT }\end{array}$ & AT & BI & 0.82 & $* * *$ & 178 \\
\hline 2 & Liebana-cabanillas (2015) & $\begin{array}{l}\text { TAM, TRA, } \\
\text { IDT }\end{array}$ & AT & BI & 0.917 & $<0.001$ & 168 \\
\hline 3 & Hossain \& Mahmud (2016) & TAM + AT & AT & BI & 0.797 & 0.000 & 75 \\
\hline 4 & Schierz et. al (2010) & $\begin{array}{l}\text { TAM, TRA, } \\
\text { IDT }\end{array}$ & AT & BI & 0.24 & $\leq .01$ & 1447 \\
\hline 5 & Hongxia et. al (2011) & UTAUT & CO & BI & -0.27 & $<.01$ & 186 \\
\hline 6 & Lu et al. (2011) & $\begin{array}{l}\text { Trust } \\
\text { Transfer } \\
\text { Theory + } \\
\text { IDT }\end{array}$ & PCO & BI & -0.072 & $<0.05$ & 961 \\
\hline 7 & $\begin{array}{l}\text { Phonthanukitithaworn et. al } \\
\text { (2015) }\end{array}$ & $\begin{array}{l}\text { TAM, TRA, } \\
\text { IDT }\end{array}$ & PCO & BI & -0.128 & $<0.05$ & 265 \\
\hline 8 & Zhou (2011) & TAM & PCO & UI & -0.26 & $<0.001$ & 277 \\
\hline 9 & Yang et.al (2011) & IDT & PFE & BI & -0.163 & $<0.05$ & 157 \\
\hline
\end{tabular}

\footnotetext{
${ }^{1}$ http://cashlessindia.gov.in/digital payment methods.html
} 


\begin{tabular}{c|l|l|l|c|c|c|c}
\hline 10 & Yang et al (2012) & IDT & PFE & BI & -0.071 & $<0.05$ & 483 \\
\hline 11 & Yang et al (2012) & IDT & PFE & BI & -0.013 & ns & 156 \\
\hline 12 & Liu (2012) & IDT & MO & BI & 0.143 & $<0.05$ & 177 \\
\hline 13 & Schierz et. al (2010) & $\begin{array}{l}\text { TAM, TRA, } \\
\text { IDT }\end{array}$ & IMO & BI & 0.07 & $<0.01$ & 1447 \\
\hline 14 & Liebana-cabanillas (2015) & $\begin{array}{l}\text { TAM, TRA, } \\
\text { IDT }\end{array}$ & IMO & BI & 0.032 & 0.768 (ns) & 168 \\
\hline 15 & Oliveira et al. (2016) & $\begin{array}{l}\text { UTAUT2, } \\
\text { IDT }\end{array}$ & PV & BI & 0.03 & ns & 301 \\
\hline 16 & Slade et al. (2015a) & UTAUT2 & PV & BI & -0.024 & 0.847 (ns) & 244 \\
\hline 17 & Makki et al (2016) & SE + Risk & IN & BI & 0.38 & $<0.01$ & 450 \\
\hline 18 & Slade et al. (2015b) & UTAUT & IN & BI & 0.22 & $<0.001$ & 268 \\
\hline 19 & Oliveira et al. (2016) & UTAUT2, & IN & BI & 0.16 & $<0.01$ & 301 \\
\hline 20 & $\begin{array}{l}\text { Ihakur \& Srivastava } \\
\text { (2014) }\end{array}$ & TAM & PIN & BI & 0.13 & $<0.001$ & 803 \\
\hline 21 & Liebana-cabanillas (2015) & TAM, TRA, & PIN & BI & 0.244 & 0.014 & 168 \\
\hline 22 & Yang et al (2012) & IDT & PIN & BI & 0.2 & $<0.001$ & 483 \\
\hline 23 & Yang et al (2012) & IDT & PIN & BI & 0.263 & $<0.01$ & 156 \\
\hline
\end{tabular}

Legend: AT = Attitude; $\beta=$ Path coefficient (Beta); $\mathrm{BI}=$ Behavioural Intention; $\mathrm{C}=\mathrm{Cost}$; $\mathrm{DV}=$ Dependent Variables; IDT = Innovation Diffusion Theory; IN=Innovativeness; IV=Independent Variable; IMO=Individual Mobility; MO=Mobility; ns=non significant; $p=$ Significance; PCO=Perceived Cost; PFE=Perceived Fee; PIN=Personal Innovativeness; PV=Perceived Value; SE = Self Efficacy; TAM = Technology Acceptance Model; TPB = Theory of Planned Behaviour; TRA = Theory of Reasoned Action; $\mathrm{TU}=$ Theory Used; UI=Usage Intention; UTAUT = Unified Theory of Acceptance and Usage of Technology; UTAUT2 = Unified Theory of Acceptance and Use of Technology 2

Table 3 presents the results generated from the meta-analysis. In addition to the independent (IV) and dependent (DV) variables, the table presents the number of times for the specific relationships examined, total sample size (TSS) for relationships across different studies, effect size $(\beta), 95 \%$ lower $(\mathrm{L}(\beta))$ and upper $\mathrm{U}(\beta)$ confidence intervals and significance level for effect size $(\beta)$ (i.e. $p(E S))$ as part of meta-analysis for all relationships examined.

Table 3: Meta-analysis Results

\begin{tabular}{c|c|c|c|c|c|c|c}
\hline IV & DV & TSS & $\#$ & Effect Size ( $\beta)$ & $\mathbf{9 5 \%}$ L( $\beta$ & $\mathbf{9 5 \% ~ U ( \beta ) ~}$ & $\mathbf{p ( E S )}$ \\
\hline ATT & BI & 1868 & 4 & 0.767 & 0.279 & 0.940 & 0.006 \\
\hline COS & BI & 2485 & 7 & -0.135 & -0.203 & -0.066 & 0.000 \\
\hline MOB & BI & 1792 & 3 & 0.074 & 0.027 & 0.120 & 0.002 \\
\hline PV & BI & 545 & 2 & 0.006 & -0.078 & 0.090 & 0.892 \\
\hline INN & BI & 2629 & 7 & 0.227 & 0.152 & 0.300 & 0.000 \\
\hline
\end{tabular}

[Legend: \#: Number of studies; ATT: Attitude; COS: Cost; D.V.: Dependant variable; ES( $\beta$ ): Metaanalysis effect size; INN: Innovativeness/Innovation; I.V.: Independent Variable; LL: Lower Limit (Beta); MOB: Mobility; p(ES): Meta-analysis significance; PV: Price Value; TSS.: Total sample size; UL: Upper Limit (Beta)] 
The meta-analysis indicates that five from six relationships are significant. There are relatively strong links between attitude and behavioral intention $(\beta=0.767, \mathrm{p}=0.006)$ and innovativeness and intention $(\beta=0.227, p=0.000)$. Two relationships (Cots to BI and Mobility to BI) are found to be overall significant but with relatively low strength in terms of effect size. The results also demonstrate that the cost has negative influence on BI. The findings also suggest that cumulative effect of causal relationship between Perceived Value (PV) and BI was found to be non-significant.

Moreover, the $95 \%$ confidence intervals for the effect size $(\beta)$ between each pair of variable presented in Table 3 indicate that their range difference (i.e. 95\% High $(\beta)$ $95 \%$ Low $(\beta))$ of less than two is narrow enough to provide one confidence to the level of variance that could be explained.

Figure 1 presents a meta-analytic model with antecedents of BI for digital payment methods. This figure provides a visual representation of all relationships (strengths in terms of correlation coefficients and significance) examined in this study. As presented in Table 3, the model clearly indicates that attitude, cost, mobility and innovativeness are significant predictors of BI. Contrastingly, PV has non-significant effect on BI.

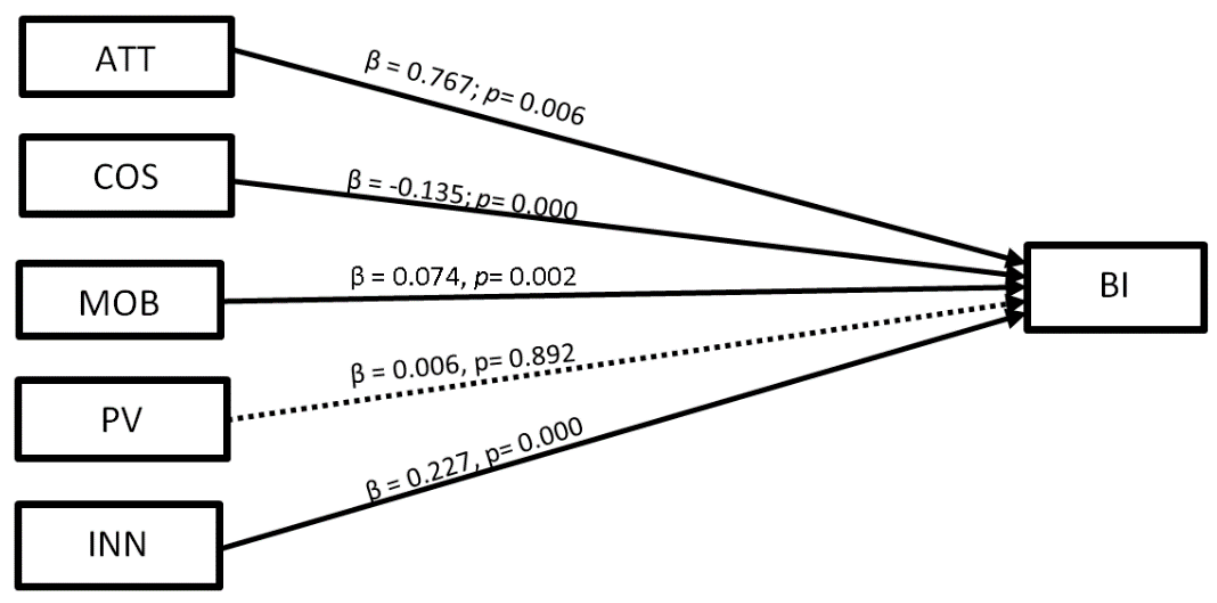

Fig 1: Influence of Attitude, Cost, Mobility, Price Value and Innovativeness as per Results Obtained from Meta-analysis.

\section{Conclusions}

This study has performed the meta-analysis of all 23 studies that have examined influence of attitude, cost, mobility, price value and innovativeness on behavioural intention to adopt digital (m-payment) systems. The findings from this research suggest that attitude, cost, mobility and innovativeness are significant antecedents of consumers' intention to adopt digital (m-payment) systems. However, effect of price value on consumers' intention to adopt was found as non-significant. Both attitude and innovativeness emerged as stronger predictors in comparison to cost and mobility. Although, effect of cost is relatively less strong (yet significant), results 
confirmed that it has negative influence on the intention to adopt. Hence, it is recommended that future studies employing intention-based theories/models for examining digital (mobile) payment adoption should integrate attitude and innovativeness as antecedents of intention along with other standard antecedents from respective theories/models. Cost/perceived cost/perceived fee should be considered as an external construct in an adoption model only when there is some form of charge/fee/commission being deducted per transaction either by mobile payment providers and/or their partners. Mobility construct should be carefully considered in terms of its measurements utilised to collect data and context of the study in order to gain stronger effect. Finally, it would be fruitful not to utilise price value construct due to its inconsistent and non-significant performance. Both cost and price value are conceptually similar in nature, but cost is better defined than latter. For this reason, it would be better to consider cost as an alternative to price value when determining intention to adopt mobile payment systems.

\subsection{Limitations and Future Research Directions}

There are few limitations that need to be accounted when interpreting results of this study. Only a limited number of studies have utilised antecedents meta-analysed in this research, so results of this study may not hold in differing contexts. So further observations and analysis are needed to confirm if results of this study are applicable in diverse contexts. The future research may also increase the number of studies used for meta-analysis by considering other forms of digital payment ecosystems and emerging FinTech applications. This study has utilised only Scopus database for identifying relevant research articles so studies that are not indexed in this database would have been excluded from being considered in this meta-analysis. The future research can comprehensively search the related keywords across all other databases and Google Scholar to maximize the number of potential studies to perform metaanalysis. The future research can also collect primary data for different constructs presented in the proposed conceptual model and validate the performance of the model.

\section{References}

1. Dwivedi, Y. K., Rana, N. P., Jeyaraj, A., Clement, M., \& Williams, M. D.: Re-examining the Unified Theory of Acceptance and Use of Technology (UTAUT): Towards a Revised Theoretical Model. Information Systems Frontiers 17(1), 143-157(2016).

2. Hongxia, P., Xianhao, X., \& Weidan, L. (2011, May). Drivers and barriers in the acceptance of mobile payment in China. In E-Business and E-Government (ICEE), 2011 International Conference on (pp. 1-4). IEEE

3. Hossain, R., \& Mahmud, I. (2016). Influence of cognitive style on mobile payment system adoption: An extended technology acceptance model. In Computer Communication and Informatics (ICCCI), 2016 International Conference on (pp. 1-6). IEEE

4. Kapoor, K.K., Dwivedi, Y.K., \& Williams, M.D. (2014a). Innovation adoption attributes: a review and synthesis of research findings. European Journal of Innovation Management, 17(3), 327-348.

5. Kapoor, K. K., Dwivedi, Y.K., \& Williams, M. D. (2014). Rogers' innovation adoption attributes: a systematic review and synthesis of existing research. Information Systems Management, 31(1), 74-91. 
6. Liébana-Cabanillas, F., Ramos de Luna, I., \& Montoro-Ríos, F. J. (2015b). User behaviour in QR mobile payment system: the QR Payment Acceptance Model. Technology Analysis \& Strategic Management, 27(9), 1031-1049

7. Liu, B. (2012, October). Understanding Consumers' Intention to Use Mobile Payment Services: The Perspective of University Students in Northern Jiangsu Area. In Proceedings of Second International Conference on Business Computing and Global Informatization (BCGIN), 2012 (pp. 257-260). IEEE

8. Lu, Y., Yang, S., Chau, P. Y., \& Cao, Y. (2011). Dynamics between the trust transfer process and intention to use mobile payment services: A cross-environment perspective. Information \& Management, 48(8), 393-403.

9. Makki, A. M., Ozturk, A. B., \& Singh, D. (2016). Role of risk, self-efficacy, and innovativeness on behavioral intentions for mobile payment systems in the restaurant industry. Journal of foodservice business research, 19(5), 454-473.

10. Oliveira, T., Thomas, M., Baptista, G., \& Campos, F. (2016). Mobile payment: Understanding the determinants of customer adoption and intention to recommend the technology. Computers in Human Behavior, 61, 404-414

11. Patil, P. P., Dwivedi, Y. K., \& Rana, N. P. (2017, November). Digital Payments Adoption: An Analysis of Literature. In Conference on e-Business, e-Services and e-Society (pp. 6170). Springer, Cham.

12. Phonthanukitithaworn, C., Sellitto, C., \& Fong, M. (2015). User intentions to adopt mobile payment services: A study of early adopters in Thailand. The Journal of Internet Banking and Commerce, 20(1), 1-29.

13. Rosenthal, R. 1991. "Meta-analysis: a review. Psychosomatic medicine.

14. Rosenthal, R., and DiMatteo, M. R. 2001. "Meta-analysis: Recent developments in quantitative methods for literature reviews,” Annual review of psychology (52:1), pp. 5982.

15. Schierz, P. G., Schilke, O., \& Wirtz, B. W. (2010). Understanding consumer acceptance of mobile payment services: An empirical analysis. Electronic Commerce Research and Applications, 9(3), 209-216

16. Slade, E., Williams, M., Dwivedi, Y., \& Piercy, N. (2015a). Exploring consumer adoption of proximity mobile payments. Journal of Strategic Marketing, 23(3), 209-223.

17. Slade, E. L., Dwivedi, Y. K., Piercy, N. C., \& Williams, M. D. (2015b). Modeling consumers' adoption intentions of remote mobile payments in the United Kingdom: extending UTAUT with innovativeness, risk, and trust. Psychology \& Marketing, 32(8), 860-873.

18. Slade E, Williams MD \& Dwivedi YK (2014). Devising a research model to examine adoption of mobile payments: An extension of UTAUT2. The Marketing Review, 14 (3), 310-335.

19. Slade E, Williams MD \& Dwivedi YK (2013). Mobile payment adoption: Classification and review of the extant literature. The Marketing Review, 13(2), 167-190

20. Thakur, R., \& Srivastava, M. (2014). Adoption readiness, personal innovativeness, perceived risk and usage intention across customer groups for mobile payment services in India. Internet Research, 24(3), 369-392.

21. Tian, Y., \& Dong, H. (2013). An analysis of key factors affecting user acceptance of mobile payment. In Informatics and Applications (ICIA), 2013 Second International Conference on (pp. 240-246). IEEE

22. Wolf, F. M. 1986. Meta-analysis: Quantitative methods for research synthesis. Sage.

23. Yang, S., Cao, Y., Mao, W., Zhang, R., \& Luo, L. (2011, November). Determinants of behavioral intention to mobile payment: Evidence from China. In Advanced Information Management and Service (ICIPM), 2011 7th International Conference on (pp. 151-154). IEEE. 
24. Yang, S., Lu, Y., Gupta, S., Cao, Y., \& Zhang, R. (2012). Mobile payment services adoption across time: An empirical study of the effects of behavioral beliefs, social influences, and personal traits. Computers in Human Behavior, 28(1), 129-142

25. Zhou, T. (2011). The effect of initial trust on user adoption of mobile payment. Information Development, 27(4), 290-300 